\title{
Discovering Differences in Patients with Uveitis through Typical Testors by Class
}

\author{
José Fco. Martínez-Trinidad, Miriam Velasco-Sánchez², E. E. Contreras-Arevalo² \\ ${ }^{1}$ Centro de Investigación en Computación, IPN \\ Juan de Dios Batiz s/n esq. Othón de Mendizabal, UPALM; C.P. 07738, México D.F. \\ e. mail: fmartine@cic.ipn.mx \\ ${ }^{2}$ Fundación Hospital Nuestra Señora de la Luz (FHNSL) \\ Ezequiel Montes No. 135, Col. Tabacalera, CP 06030, México D.F.
}

\begin{abstract}
An analysis of clinical features on patients with uveitis attending to their localization through typical testors is presented. The main goal for the physician was to discover feature sets such that distinguish four groups of patients with uveitis. In order to solve the problem was used the Testor Theory in the Logical Combinatorial Pattern Recognition context.
\end{abstract}

\section{Introduction to Clinical Problem}

Uveitis is a group of diseases that affect typically the intermediate layer of the eye. This pathology represents between $3 \%$ and $5 \%$ of ophthalmological consultation. Uveitis had been subject of different classifications the most frequently is based in the location of the lesion in anterior uveitis, intermediate uveitis and posterior uveitis [1].

Uveitis can affect corneal endothelium by inflammation or retrokeratic deposits. Endothelial damage depends upon the intensity and location of the inflammation $[2,3]$. We studied a group of patients with active uveitis by using specular microscopy. The specular microscopy is a procedure that was initially used by David Maurice in 1968 [4]. In our study we included patients with anterior uveitis, pars planitis and toxoplasmosis.

The goal of our research was to discover feature sets that allow us distinguishing patients in the following four groups of uveitis: pars planitis, toxoplasmosis, anterior uveitis (in patients before 40 years old) and anterior uveitis (after 40 years old).

\section{Typical Testors by Class}

The Logical Combinatorial Pattern Recognition (LCPR) has as main characteristic that allow us handle information of the objects (their descriptions) under study in terms of a set of features or attributes [5]. These features may be of any nature, that is to say, numeric or not numeric. It allows us to model the problem according to the specialist do it in the practice, instead of force the mathematical tools to adapt to the practical problem.

D.A. Zighed, J. Komorowski, and J. Zytkow (Eds.): PKDD 2000, LNAI 1910, pp. 524-529, 2000.

(C) Springer-Verlag Berlin Heidelberg 2000 
Let $\Omega=\left\{O_{l}, \ldots, O_{m}\right\}$ a finite set of objects. Let $R=\left\{x_{l}, \ldots, x_{n}\right\}$ a set of features, each feature $x_{i}$ has associated a set of admissible values denoted as $M_{i} i=1, \ldots, n$. A description $I\left(O_{p}\right)$ is defined for each object $O_{p} p=1, \ldots, m$., as a finite sequence of values of features $\left(x_{l}\left(O_{p}\right), \ldots, x_{n}\left(O_{p}\right)\right)$. Also for every variable is defined a comparison criterion for the admissible values $C_{i}: M_{i} \times M_{i} \rightarrow L_{i} i=1, \ldots, n$. It is known that the set $\Omega$ is divided in a finite number of subsets $K_{l}, \ldots, K_{l}$ called classes. Each class $K_{j} j=1, \ldots, l$ is defined by a number of objects. This information about objects and classes is in a learning matrix (LM) as the one shown in the Table 1.

The LCPR allows computing feature sets that distinguish objects in a class against the other classes through Testors Theory [6].

If the problem is related with Medicine and the number of the objects in each class is greater than one, it means that characterization is done on patients by means of their symptoms and signs associated with a particular disease. In this way the objects $O_{p}$ in LM are the patients, features $x_{i} i=1, \ldots, n$ are the symptoms and classes $K_{j} j=l, \ldots, l$ are the different diseases a patient can suffer.

Table 1. Learning Matrix with $m$ objects, $n$ features and $l$ classes

\begin{tabular}{ccccc}
\hline LM & Objects & \multicolumn{4}{c}{ Features } \\
& & $x_{I}$ & $\ldots$ & $x_{n}$ \\
\hline \multirow{4}{*}{$K_{I}$} & $O_{l}$ & $x_{I}\left(O_{I}\right)$ & $\ldots$ & $x_{n}\left(O_{l}\right)$ \\
& $\ldots$ & $\ldots$ & $\ldots$ & $\ldots$ \\
\hline & $O_{p}$ & $x_{I}\left(O_{p}\right)$ & $\ldots$ & $x_{n}\left(O_{p}\right)$ \\
\hline \multirow{2}{*}{$K_{l}$} & $\ldots$ & $\ldots$ & $\ldots$ & $\ldots$ \\
& $O_{q}$ & $x_{I}\left(O_{q}\right)$ & $\ldots$ & $x_{n}\left(O_{q}\right)$ \\
& $\ldots$ & $\ldots$ & & $\ldots$ \\
\hline
\end{tabular}

In this context, a set of features $\left\{x_{i 1}, \ldots, x_{i t}\right\}$ of LM is called a testor by class $(T C)$ for the class $K_{i}$ from LM if after deleting from LM all columns except $\left\{x_{i l}, \ldots, x_{i t}\right\}$, all rows of LM corresponding to $K_{i}$ are different to rows corresponding to $K_{j} j \neq i$. A $T C$ is called typical testor by class (TTC) if none of its proper subsets is a TC [7]. TTC will be used too instead of typical testors by class indistinctly.

In general, we can say that finding all typical testors of a matrix is equivalent to doing an exhaustive search on all feature subsets, which are $2^{|R|}$, where $|R|$ is $R^{\prime}$ s cardinal number. When the number of rows, columns or classes increases, the time necessary for this procedure could grow until it becomes impossible to be computed. As a consequence of this, many studies have been developed; in fact, this problem alone is a research line within Testor Theory framework [6].

Through computation of $T T C$, it is possible to discover feature sets that allow distinguishing patients in different classes.

Let $\Psi$ be the set of all $T T C$ for $K_{i} i=1, \ldots, l$, of a given problem and $\Psi(x)$ the subset of all TTC that contain feature $x$. To each feature $x$ we assign the value obtained by the equation 1 .

$$
F(x)=|\Psi(x)| /|\Psi|
$$

The value $F(x)$ is called informational weight based in the apparition frequency of the feature in the TTC and we identify it as a measure of its importance [6]. In 
addition, we assign to each TTC a weight based in the informational weight of the features as follows:

$$
\sigma(t)=\frac{1}{|t|} \sum_{x_{i} \in t} F\left(x_{i}\right)
$$

It is clear according to this approach that between more frequent is a feature in the set of TTC (the feature is more useful than other to distinguish objects belonging to different classes) most important will be it. Consequently the TTC with the highest weight will be those containing features with the highest weight. Therefore, we consider that a typical testor with highest weight is more important to distinguish objects belonging to different classes than a typical testor with low weight.

\section{Methodology}

In our study, we include patients treated in the FHNSL from March to August in 1999. These patients satisfied the following clinical criteria: active uveitis, first inflammatory manifestation, specular microscopy, fulfillment of treatment, complete clinical file. We exclude those patients with: diabetes mellitus of any type, contact lens user, associated or previous ocular or corneal pathology, previous ocular trauma or ocular surgery, other systemic pathologies (neurological disease).

In the specular microscopy, the features shown in the table 2 were analyzed.

Table 2. Clinical features used to describe patients with uveitis

\begin{tabular}{lll}
\hline \multicolumn{1}{c}{ Feature } & \multicolumn{1}{c}{ Admissible values } & \multicolumn{1}{c}{ Type } \\
\hline Age $(A)$ & $10-80$ & Quantitative \\
Gender $(G)$ & M= Male, F= Female & Qualitative Boolean \\
Cellular Density $(C D)$ & $500-2500$ & Quantitative \\
Pleomorphism $(P l)$ & absent light moderate severe & Qualitative Ordinal \\
Polimegathism $(P o)$ & absent light moderate severe & Qualitative Ordinal \\
Tyndall $(T)$ & -+++++ & Qualitative Ordinal \\
Flare $(F)$ & -++++++ & Qualitative Ordinal \\
Guttatas $(G u)$ & 0 I II III & Qualitative Ordinal \\
\hline
\end{tabular}

From the 38 studied patients, 5 were eliminated (because them did not satisfy clinical criteria) and 33 were considered. The patients were separated in four classes taking account the localization of the uveitis as is shown in the table 3.

Note that the classes toxoplasmosis and pars planitis have only three and four patients respectively, nevertheless the physicians consider that these descriptions of patients are representatives of these groups of patients.

As first step, we modeled jointly with the specialists, the comparison criteria for the values of the features. For qualitative features was used a comparison criterion based in the matching, see equation (3).

$$
C_{x_{i}}\left(x_{i}\left(I\left(O_{i}\right)\right), x_{i}\left(I\left(O_{j}\right)\right)\right)=\left\{\begin{array}{cc}
1 & \text { if } x_{i}\left(I\left(O_{i}\right)\right) \neq x_{i}\left(I\left(O_{j}\right)\right) \\
0 & \text { otherwise }
\end{array}\right.
$$


In the case of quantitative features was used a comparison criterion with threshold, that is to say, two values are different if the absolute difference between them is greater than a threshold, see equation (4).

$$
C_{x_{i}}\left(x_{i}\left(I\left(O_{i}\right)\right), x_{i}\left(I\left(O_{j}\right)\right)\right)=\left\{\begin{array}{cc}
1 & \text { if }\left|x_{i}\left(I\left(O_{i}\right)\right)-x_{i}\left(I\left(O_{j}\right)\right)>\varepsilon\right| \\
0 & \text { otherwise }
\end{array}\right.
$$

The specialists according to their expertise proposed the threshold for this criterion. So the threshold used for age feature was $\varepsilon=5$ and $\varepsilon=100$ for cellular density feature.

Table 3. Sample of patients with uveitis

\begin{tabular}{|c|c|c|c|c|c|c|c|c|c|}
\hline & Num & A & G & CD & $\mathrm{Pl}$ & Po & $T$ & F & $\mathrm{Gu}$ \\
\hline & P1 & 12 & F & 1500 & light & moderate & - & - & I \\
\hline \multirow[t]{3}{*}{ Pars Planitis } & $\mathrm{p} 2$ & 12 & M & 1500 & absent & absent & ++ & - & 0 \\
\hline & P3 & 35 & M & 2200 & absent & absent & ++ & - & 0 \\
\hline & P4 & 13 & F & 2000 & light & light & ++ & - & 0 \\
\hline \multirow{3}{*}{ Toxoplasmosis } & P5 & 20 & $\bar{M}$ & 1400 & absent & absent & + & - & 0 \\
\hline & P6 & 16 & $\mathrm{~F}$ & 1000 & severe & severe & + & - & 0 \\
\hline & P7 & 30 & $\mathrm{~F}$ & 1200 & absent & light & + & - & 0 \\
\hline \multirow{9}{*}{$\begin{array}{l}\text { Anterior } \\
\text { Uveitis }<=40\end{array}$} & P8 & 38 & $\bar{M}$ & 1200 & light & light & + & - & I \\
\hline & P9 & 21 & $\mathrm{~F}$ & 1400 & light & light & + & ++ & I \\
\hline & P10 & 22 & M & 1200 & absent & light & - & - & 0 \\
\hline & P11 & 30 & M & 1200 & light & light & +++ & - & I \\
\hline & P12 & 38 & $\mathrm{~F}$ & 1200 & moderate & light & ++ & +++ & II \\
\hline & P13 & 24 & M & 800 & severe & severe & ++ & ++ & I \\
\hline & P14 & 30 & $\mathrm{~F}$ & 1000 & severe & severe & ++ & + & II \\
\hline & P15 & 19 & $\mathrm{~F}$ & 1200 & severe & severe & + & - & I \\
\hline & P16 & 40 & $\mathrm{~F}$ & 1200 & light & light & ++ & - & I \\
\hline \multirow{17}{*}{$\begin{array}{l}\text { Anterior } \\
\text { Uveitis }>40\end{array}$} & P17 & 52 & $\mathrm{~F}$ & 600 & severe & severe & + & - & III \\
\hline & P18 & 70 & $\mathrm{~F}$ & 600 & light & severe & +++ & ++ & III \\
\hline & P19 & 49 & M & 600 & moderate & severe & +++ & ++ & III \\
\hline & P20 & 66 & $\mathrm{~F}$ & 700 & moderate & severe & + & - & II \\
\hline & P21 & 44 & M & 1200 & light & light & ++ & - & 0 \\
\hline & P22 & 53 & $\mathrm{~F}$ & 900 & light & moderate & +++ & +++ & II \\
\hline & P23 & 49 & $\mathrm{~F}$ & 1200 & light & light & ++ & + & II \\
\hline & P24 & 80 & $\mathrm{~F}$ & 600 & severe & severe & + & - & II \\
\hline & P25 & 45 & $\mathrm{~F}$ & 1200 & absent & absent & ++ & - & 0 \\
\hline & P26 & 47 & F & 800 & severe & severe & ++ & - & II \\
\hline & P27 & 41 & M & 1200 & light & light & +++ & +++ & I \\
\hline & P28 & 43 & M & 1400 & moderate & absent & ++ & +++ & 0 \\
\hline & P29 & 42 & M & 1000 & moderate & light & ++ & + & II \\
\hline & P30 & 70 & M & 600 & moderate & severe & + & - & II \\
\hline & P31 & 44 & $\mathrm{~F}$ & 800 & moderate & moderate & ++ & ++ & I \\
\hline & P32 & 55 & F & 900 & severe & moderate & ++ & ++ & II \\
\hline & P33 & 42 & M & 700 & moderate & severe & + & ++ & III \\
\hline
\end{tabular}

It exists several algorithms to compute the typical testors [8], in this particular problem was applied the CC algorithm. The TTC for the four classes of patients are shown in the table 4.

\section{Discussion and Conclusions}

In the first column of tables $4 \mathrm{a}$ to $4 \mathrm{~d}$, we can see the sets of features that allow us to distinguish the patients of the respective class against the rest patients (TTC). In the fourth column appears the weight associated to the feature in the column third. 
Remind that the weight associated to the features is computed using (1). On basis of this weight is computed the weight associated to the typical testor through (2), it appears in the second column. Note that if we observe the subdescriptions in a particular class, attending only to the features in the typical testor for this class, all those are different to the subdescriptions in the other classes. Therefore, through TTC computation it is possible discover the sets of features that allow us detect the differences between the patients under study.

Table 4. Typical testors by class for 4a) Pars Planitis; 4b) Toxoplasmosis; 4c)Anterior uveitis $<=40$ and 4 d) Anterior uveitis $>40$ classes.

\begin{tabular}{llll}
\hline Typical Testor & Weight & Feature & Weight \\
\hline$\{\mathrm{CD}, \mathrm{T}, \mathrm{F}\}$ & 0.4583 & $\mathrm{~A}$ & 0.75 \\
$\{\mathrm{CD}, \mathrm{Pl}, \mathrm{Tl}\}$ & 0.4167 & $\mathrm{G}$ & 0 \\
$\{\mathrm{~A}, \mathrm{~T}, \mathrm{Gu}\}$ & 0.5416 & $\mathrm{CD}$ & 0.625 \\
$\{\mathrm{~A}, \mathrm{Po}\}$ & 0.4375 & $\mathrm{Pl}$ & 0.375 \\
$\{\mathrm{~A}, \mathrm{Pl}, \mathrm{T}\}$ & 0.5833 & $\mathrm{Po}$ & 0.125 \\
$\{\mathrm{~A}, \mathrm{CD}, \mathrm{Gu}\}$ & 0.5416 & $\mathrm{~T}$ & 0.625 \\
$\{\mathrm{~A}, \mathrm{CD}, T\}$ & 0.6666 & $\mathrm{~F}$ & 0.125 \\
$\{\mathrm{~A}, \mathrm{CD}, \mathrm{Pl}\}$ & 0.5833 & $\mathrm{Gu}$ & 0.25 \\
\hline
\end{tabular}

\begin{tabular}{llll}
\hline Typical Testor & Weight & Feature & Weight \\
\hline$\{\mathrm{T}, \mathrm{G}\}$ & 0.49995 & $\mathrm{~A}$ & 0.5714 \\
$\{\mathrm{CD}, \mathrm{PO}, \mathrm{T}\}$ & 0.52376 & $\mathrm{G}$ & 0 \\
$\{\mathrm{CD}, \mathrm{Pl}, \mathrm{T}\}$ & 0.52376 & $\mathrm{CD}$ & 0.7142 \\
$\{\mathrm{~A}, \mathrm{Po}, \mathrm{Gu}\}$ & 0.42853 & $\mathrm{Pl}$ & 0.2857 \\
$\{A, C D, G u\}$ & 0.5713 & $\mathrm{Po}$ & 0.2857 \\
$\{\mathrm{~A}, \mathrm{CD}, \mathrm{T}, \mathrm{F}\}$ & 0.49995 & $\mathrm{~T}$ & 0.5714 \\
$\{\mathrm{~A}, \mathrm{CD}, \mathrm{Pl}\}$ & 0.5237 & $\mathrm{~F}$ & 0.1428 \\
& & $\mathrm{Gu}$ & 0.4285 \\
\hline
\end{tabular}

\begin{tabular}{llll}
\multicolumn{4}{c}{ 4a } \\
\hline Typical Testor & Weight & Feature & Weight \\
\hline$\{\mathrm{Po}, \mathrm{T}, \mathrm{F}, \mathrm{Gu}\}$ & 0.7083 & $\mathrm{~A}$ & 0.6666 \\
$\{\mathrm{Pl}, \mathrm{T}, \mathrm{F}, \mathrm{Gu}\}$ & 0.6666 & $\mathrm{G}$ & 0 \\
$\{A, T, F, \mathrm{Gu}\}$ & 0.7916 & $\mathrm{CD}$ & 0.3333 \\
$\{\mathrm{~A}, \mathrm{Po}, \mathrm{F}, \mathrm{Gu}\}$ & 0.7083 & $\mathrm{Pl}$ & 0.1666 \\
$\{\mathrm{~A}, \mathrm{CD}, \mathrm{F}, \mathrm{Gu}\}$ & 0.7083 & $\mathrm{Po}$ & 0.3333 \\
$\{\mathrm{~A}, \mathrm{CD}, \mathrm{T}, \mathrm{Gu}\}$ & 0.6666 & $\mathrm{~T}$ & 0.6666 \\
& & $\mathrm{~F}$ & 0.8333 \\
& & $\mathrm{Gu}$ & 1 \\
\hline
\end{tabular}

$4 \mathrm{c}$

\begin{tabular}{llll}
\hline & \multicolumn{2}{c}{ 4b } & \\
\hline Typical Testor & Weight & Feature & Weight \\
\hline$\{\mathrm{CD}, \mathrm{Po}, \mathrm{T}, \mathrm{F}, \mathrm{Gu}\}$ & 0.72 & $\mathrm{~A}$ & 0.4 \\
$\{\mathrm{CD}, \mathrm{Pl}, \mathrm{T}, \mathrm{F}, \mathrm{Gu}\}$ & 0.72 & $\mathrm{G}$ & 0 \\
$\{\mathrm{CD}, \mathrm{Pl}, \mathrm{Po}, \mathrm{F}, \mathrm{Gu}\}$ & 0.68 & $\mathrm{CD}$ & 0.8 \\
$\{A, F, G u\}$ & 0.73 & $\mathrm{Pl}$ & 0.4 \\
$\{\mathrm{~A}, \mathrm{CD}, \mathrm{T}, \mathrm{Gu}\}$ & 0.70 & $\mathrm{Po}$ & 0.4 \\
& & $\mathrm{~T}$ & 0.6 \\
& & $\mathrm{~F}$ & 0.8 \\
& & $\mathrm{G}$ & 1 \\
\hline
\end{tabular}

4d

After compute the $T T C$, it is possible to evaluate the informational weight for features based in its importance to distinguish patients of a class against the rest. Remind that we consider that between more frequent is a feature in the set of TTC, then the feature is more useful than other to distinguish objects belonging to different classes. Consequently, it is possible to use the weight of features to associate a weight to the typical testors as is expressed in (2). This weight can be interpreted as the importance that the typical testor has to distinguish patients of a particular class against the rest. In some cases may be useful only consider the TTC with highest weight (See the rows in cursive in the tables $4 a-4 d$ ).

The typical testors by class are important to select those sets of features that are most efficient to preserve class separability. So, these sets of features can be used to classify new patients.

As future work, in a second phase, we pretend to construct a computer system to realize differential diagnosis of intraocular inflammatory diseases. We will use the algorithms based in partial precedence as voting algorithms, Kora- $\Omega$ and 
representative sets [9]. These algorithms allow us in natural way consider both TTC and their weights, in order to classify new patients. The idea of these algorithms is to classify objects according to their description and their similitude with the objects already classified in the $K_{i}$ classes. The similarity is evaluated analyzing subdescriptions of objects instead of whole descriptions. The TTC define the set of features that should be compared through a convenient similarity function and the weight of the testors weigh this similarity. Therefore, It would be possible to apply any of these algorithms to LM in order to classify a new object, obtaining the decision criteria for the class it belongs to.

In this paper, a methodology to discover differences between patients with uveitis was presented. In order to solve this problem TTC were used.

The analysis here presented constitute a first step for solve the differential diagnosis of intraocular inflammatory diseases. Besides, based on this work the construction of a computer system in order to realize differential diagnosis of intraocular inflammatory diseases was proposed as future work.

Of course, we will add feedback to the process enriching jointly with the physicians the sample of patients in LM.

Finally, the methodology proposed in this paper is of extremely useful, not only to discover differences between patients with uveitis, but also, to discover differences between patients of any diseases.

\section{References}

1. American Academy Of Ophthalmology: Intraocular Inflammation And Uveitis. In Immunology (Eds. Margaret Dennit ), American Academy Of Ophthalmology Press. 1996, pp. 15-80.

2. Nozik R A.: Uveitis. In Ophthalmology Clinics Of North America. (Saunders Philadelphia) 1993, pp. 1-22, 24-50.

3. Zantos S G.: Guttate Endothelial Changes with Anterior Eye Inflammation. Br J Ophthalmol. 65 (1981) 101-103.

4. Maurice, D. M.: Cellular membrane activity in the corneal endothelium of the intact eye. Experientia. 24 (1968) 1094

5. Ortiz-Posadas M.R., Martínez-Trinidad J.F. and Ruiz-Shulcloper J: A new approach to differential diagnosis of diseases. International Journal of Bio-Medical Computing 40 (1996) 179-185.

6. Lazo-Cortes M. and Ruiz-Shulcloper.: Determining the feature relevance for non-classically described objects and a new algorithm to compute typical fuzzy testors. Pattern Recognition Letters. 16 (1995) 1259-1265.

7. Lazo-Cortes M., Douglas de la Peña, Quintana Gómez. Testores por clase. Una aplicación al Reconocimiento de caracteres. In Proceedings of the III Iberoamerican Workshop on Pattern Recognition, Politécnica México, D.F. 1998, pp. 229-236.

8. Sanchez-Díaz G. and Lazo-Cortés M.: Modelos algorítmicos paralelos y distribuidos para el cálculo de testores típicos. In Proceedings of the II Iberoamerican Workshop on Pattern Recognition, Politécnica México, D.F. 1997, pp. 135-140.

9. Ruiz-Shulcloper J. and Lazo-Cortés M.: Mathematical Algorithms for the Supervised Classification Based on Fuzzy Partial Precedence, Mathematical and Computer Modelling 29 (1999) 111-119. 